significantly improved through the development of data analysis. Narrative text mining is demanding also because of the multiplicity of languages spoken in the world.

\section{DRIVE IN DRIVE OUT COAL MINERS: AN ACCIDENT WAITING TO HAPPEN}

Jeremy Davey, Candice Potter, Kerry Armstrong. Queensland University of Technology, Centre for Accident and Road Safety

\subsection{6/injuryprev-2016-042156.880}

Background Australian mining sites and cover vast areas of the country are often located hundreds of kilometres from major centres. Thousands of mine workers reside in major population centres in coastal communities and regularly drive hundreds of kilometres to and from their workplaces at remote mine sites. This exposes many workers particularly on completion of their working week to the behaviours of high-risk fatigue and remote area driving.

Methods Data was collected using in-depth interviews $(n=37)$ and a written survey $(n=461)$ of employees from a Queensland coal mine. As well as collecting demographic and behaviour data the survey also contained constructs on the theory of planned behaviour, to examine the workers decisions about driving immediately after their rosters of 12 to $14 \mathrm{hrs}$. shifts over seven to ten day periods.

Results Workers drove an average of $473 \mathrm{~km}$ at the end of their rosters and almost one third drove over $600 \mathrm{~km}$. There was an overwhelming desire to leave site as soon as possible after rosters. This desire frequently overrides concerns about high risks associated with fatigue and remote area driving. Facilitating factors include routine, sick of being on site, to get the drive over with, and because workers perceive they are experienced drivers. There were notable variations between factors that facilitate leaving site immediately. These variations and different control beliefs are predominately due to the type of shift (i.e. day or night).

Conclusions This research identified that many workers could be driving after being awake for up to 20 hours on the last day of shift. This level of wakefulness can impair driving that is equivalent to a BAC of $0.10 \%$. The current study is understood to be the first to provide insight into the factors that facilitate and act as a barrier to mine workers driving immediately following their shift blocks. Interventions need to consider different shift types and the variations in intention and behaviour of worker commuting.

\section{PROFILE OF NON-FATAL ROAD TRAFFIC CRASHES AMONG ADOLESCENTS IN GALLE, SRI LANKA: A CROSS-SECTIONAL SURVEY}

\footnotetext{
${ }^{1,2}$ Enying Gong, ${ }^{3}$ Vijitha De Silva, ${ }^{3}$ Hemajith Tharindra, ${ }^{1}$ Catherine Staton. ${ }^{1}$ Duke University, US: ${ }^{2}$ Duke Kunshan University, China; ${ }^{3}$ Ruhuna University, Sri Lanka
}

\subsection{6/injuryprev-2016-042156.881}

Background Road traffic crashes (RTC) affect all age groups, but their impact is most striking on the young people. Sri Lanka is experiencing an epidemic of RTC. Information on the patterns of the crashes is essential to identify emerging issues and potential strategies, but few studies targeted on adolescents in Sri Lanka. The objective of this study is to describe the profile of non-fatal road traffic crashes among adolescents aged 16-18 years old in Galle, Sri Lanka and to explore related factors.

Methods We conducted a cross-sectional survey in 16 high schools in Galle, Sri Lanka during May-July, 2014. Students aged between 16-18 years old were selected to participate in the pencil-paper survey and reported their experience of RTC in the past 6 months. Descriptive analysis and logistic regression were performed by using STATA. Signed informed consents were given by all participants and the study was approved by IRB at Duke University and Ruhuna University.

Results 1370 adolescents (681 males and 689 females) with the average age 17.7 completed the survey. 206 (15.1\%) respondents self-reported being involved in crashes in the past 6 months as victimised pedestrians $(20.5 \%)$, cyclists $(21.0 \%)$ and motorcycle passengers (25.7\%). Among these victims, $47.1 \%$ often wear helmets and $15.1 \%$ often play on the roads. $25.7 \%$ of these crashes happened on the way between home and school. 98 and 7 respondents suffered minor or severe injuries respectively leading to on average 1.23 days off from the school. After controlled school as cluster, the regression model showed that males $(\mathrm{OR}=1.58,95 \% \mathrm{CI}[1.19,2.10])$ and safe-road behaviours $(\mathrm{OR}=0.78,95 \% \mathrm{CI}[0.71,0.87])$ were significantly associated with the crashes.

Conclusions RTC is one of the emerging threats to adolescents in Sri Lanka. More effective intervention should be targeted on adolescents to promote their safe behaviours on the roads and prevent them from road traffic injuries and deaths.

\section{IMPACT OF THREE WHEELER BAN POLICY ON ROAD TRAFFIC INJURIES IN KARACHI, PAKISTAN}

Fareed Ahmed, Zafar Fatmi. Aga Khan University Hospital, Karachi, Pakistan

10.1136/injuryprev-2016-042156.882

Background (issue) Ban on two wheelers or three wheelers on many roads in several Asian cites have been implicated; however their impact on road traffic injuries (RTI) have not been studied much. In Karachi, Pakistan, for past few years there is steadily increase of three wheelers as a most frequent mode of transportation. From August 2015 Sindh High Court (SHC) has ordered the authorities to take immediate action against operation of these three-wheelers, commonly known as Qingqis, across the province.

Description of the problem Frequency of RTI secondary to three wheeler (Qingqis) is one the emerging problem in our part of world. It was implicated that three-wheelers led to increase in the RTI in Karachi. However, to date no work has been done to estimate the contribution of three-wheelers on RTI in Karachi.This is (an ongoing) descriptive cross sectional study (pre and post) design, that is before and after implementation of ban policy on Qingqis using hospital based record review.

Effects This is our preliminary results on the basis of record review done from Feb. to July, 2015 (before ban policy) and from Aug. to Oct, 2015 ( after ban policy, ongoing). A total of $(\mathrm{n}=638)$ RTI reported in the period of pre-ban policy. Total fatal accident were (34.9\%) majority were due to motorbike versus(vs) cars (57\%), motorbike vs motorbike (21\%), motorbike Vs three wheelers (16\%), car vs car (5\%) while in $1 \%$ single vehicle involved. In non-fatal accident $(n=415)$ majority were involved Qingqis (71\%).In the period of post-ban policy, we have analyse the data of 3 months from Aug. to Oct. A total of $(n=261)$ RTI were reported. Fatal accident were $(31.8 \%)$ majority again from 